\title{
Influence of the Monsoon Variability and Sea Surface Temperature Front on the Explosive Cyclone Activity in the Vicinity of Japan during Northern Winter
}

\author{
Satoshi Iizuka ${ }^{1}$, Minako Shiota ${ }^{2}$, Ryuichi Kawamura ${ }^{3}$, and Hiroaki Hatsushika ${ }^{4}$ \\ ${ }^{1}$ National Research Institute for Earth Science and Disaster Prevention, Tsukuba, Japan \\ ${ }^{2}$ Muroran Local Meteorological Observatory, Japan Meteorological Agency, Muroran, Japan \\ ${ }^{3}$ Department of Earth and Planetary Sciences, Faculty of Sciences, Kyushu University, Fukuoka, Japan \\ ${ }^{4}$ Toyama Prefectural Environmental Science Research Center, Toyama, Japan
}

\begin{abstract}
The possible impact of the winter monsoon intensity and sea surface temperature (SST) gradient on the activity of explosively developing extratropical cyclones around Japan is investigated using the Weather Research Forecasting model. Two independent long-term integrations over 18 winters from 1993/94 to 2010/2011 are conducted using prescribed observed SST data (OS run) and spatially smoothed data (SS run). The OS run is successful in reproducing the spatial distributions of the explosive cyclone activity in the vicinity of Japan under both strong and weak winter monsoon conditions. Under strong monsoon conditions, the Kuroshio, the Kuroshio Extension, and the Japan Sea subpolar fronts give rise to enhanced near-surface baroclinicity through the increase in heat and moisture fluxes from the ocean surface, resulting in frequent occurrence of the explosive cyclone activity along those fronts.

(Citation: Iizuka, S., M. Shiota, R. Kawamura, and H. Hatsushika, 2013: Influence of the monsoon variability and sea surface temperature front on the explosive cyclone activity in the vicinity of Japan during northern winter. SOLA, 9, 1-4, doi:10.2151/sola. 2013-001.)
\end{abstract}

\section{Introduction}

Explosively developing cyclones frequently appear in the vicinity of Japan during northern winter (e.g., Chen et al. 1992; Yoshida and Asuma 2004). The presence of both the East Asian winter monsoon circulation and the warm currents of the Kuroshio and the Kuroshio Extension is expected to reinforce baroclinicity in the lower troposphere, providing favorable environmental conditions for the explosive cyclone activity around Japan. As for the winter monsoon, Yoshiike and Kawamura (2009) demonstrated that, when the monsoon is stronger than usual, the explosive cyclone activity tends to concentrate in the vicinity of Japan, whereas, when the monsoon is weak, it spreads over a broader area. Generally, the origin of the explosive cyclones is traced upstream to the vicinity of the East China Sea and the Kuroshio. Shiota et al. (2011) showed that the occurrence of surface cyclone tends to concentrate over the East China Sea during the strong phase of the East Asian winter monsoon activity, whereas it spreads zonally along the Kuroshio to the south of Japan in the weak monsoon phase. They also suggested that, when the monsoon is strong, the enhanced baroclinic zone along the Kuroshio south of Japan provides favorable conditions for the rapid development of the surface cyclones that originate over the East China Sea and then migrate northeastward. However, since these two are observational studies, further clarifications are required using numerical models. Xie et al. (2002) reported that the steepness of the sea surface temperature (SST) front over the East China Sea

Corresponding author: Ryuichi Kawamura, Department of Earth and Planetary Sciences, Faculty of Sciences, Kyushu University, 6-10-1 Hakozaki, Higashi-ku, Fukuoka 812-8581, Japan. E-mail: kawamura@geo.kyushu-u. ac.jp. (C2013, the Meteorological Society of Japan. contributes to the development of surface cyclones that appear around Taiwan; however, only one case, that in February 2001, was examined. Multiple simulations provide for more reliable results.

Thus, the purpose of this study is (1) to examine the influence of the SST steepness on the explosive cyclone activity by comparing the results of long-term simulations using observed SST and spatially smoothed SST data, aided by a regional atmospheric model, and (2) to clarify how its influence is modified through the change in the lower tropospheric baroclinicity under strong and weak winter monsoon conditions.

\section{Model and data used}

The model experiments are carried out using the Advanced Research Weather Forecasting (WRF) Model (Skamarock et al. 2008). The model was run in the vicinity of Japan divided into $181 \times 181$ grids with a spatial resolution of $20 \mathrm{~km}$. The model uses 28 vertical levels, with the top level at $50 \mathrm{hPa}$. The physical parameterization schemes used in this study include the Rapid Radiative Transfer Model (RRTM) longwave radiation (Mlawer et al. 1997) and Goddard shortwave radiation (Chou and Suarez 1994) schemes, the "Noah" land surface model, the modified version of the Kain-Fritsch scheme (Kain and Fritsch 1990), and the microcloud physics proposed by Morrison et al. (2005). The planetary boundary layer (PBL) scheme was the Yonsei University scheme (Ysu et al. 2006). The initial and lateral boundary conditions of the model were provided by the Japanese Long-term Reanalysis project (JRA-25) (Onogi et al. 2007) and the Japan Meteorological Agency (JMA) Climate Data Assimilation System (JCDAS) data for all experiments. Eighteen winters for the period from 1993/1994 to 2010/2011 were simulated, and a segmented integration of the models was conducted every year from 21 November to 1 March to reduce the computational burden. In one experiment (OS run), the daily optimal interpolation SST (OISST) data based only on the Pathfinder Advanced Very High Resolution Radiometer (AVHRR) (Reynolds et al. 2007) with a spatial grid resolution of $0.25^{\circ}$ was used. In the smoothed SST experiment (SS run), the SST fields over the whole domain were replaced by an average of the values in a $17 \times 17$ square of cells $\left(4.25^{\circ} \times 4.25^{\circ}\right)$ centered on the cell in question. The smoothing eliminated the sharp SST gradients associated with the oceanic fronts.

Following the criteria of Yoshida and Asuma (2004), a rapidly developing extratropical cyclone is identified as an explosive cyclone if the subsequent deepening rate $(\varepsilon)$ exceeds $1 \mathrm{hPa} \mathrm{hr}^{-1}$.

$$
\varepsilon=\left[\frac{p(t-6)-p(t+6)}{12}\right] \frac{\sin 60^{\circ}}{\sin \phi},
$$

where $p$ is the sea level pressure (SLP) at the center of cyclone, $t$ is the time in hours, and $\phi$ is the latitude at the cyclone center. The initial appearance of an extratropical cyclone is defined when an hourly SLP at any grid point is at least $1.0 \mathrm{hPa}$ lower than the value at surrounding grid points. Tracks are constructed by a nearest-neighbor search in the data field around a cyclone position. 
(a) OS run

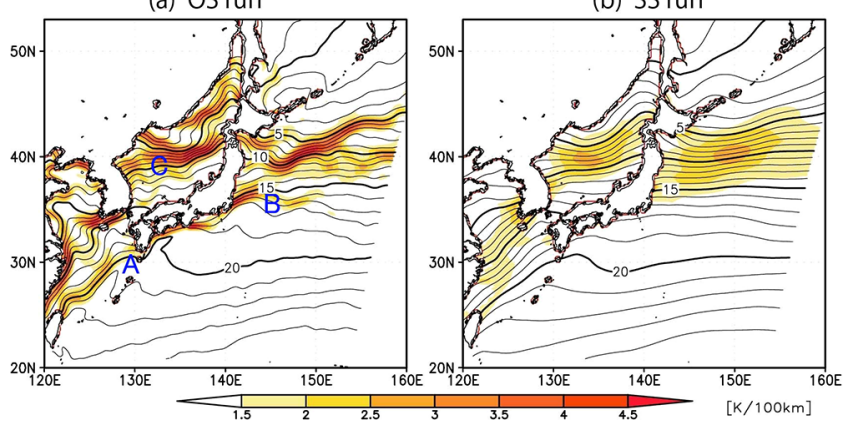

Fig. 1. (a) Spatial pattern of OISST averaged over 18 winters (DJF) from $1993 / 94$ to 2010/2011. The contour interval is $1 \mathrm{~K}$. Shading denotes the horizontal SST gradient $(\mathrm{K} / 100 \mathrm{~km})$. The letters A, B and C denote the locations of the Kuroshio, the Kuroshio Extension and the Japan Sea subpolar fronts, respectively. (b) As in Fig. 1a but for horizontally smoothed OISST.

\section{Results}

\subsection{Climatological features}

The spatial distributions of SST averaged over 18 winters (DJF) from 1993/94 to 2010/2011 for both OS and SS runs are presented in Fig. 1. The major SST fronts, such as the Kuroshio front in the East China Sea, the Kuroshio Extension front, and subpolar fronts over the central Japan Sea and to the east of northern Japan, are well defined in the OS run, whereas those fronts are smoothed out in the SS run. The total numbers of simulated explosive cyclones for the OS and SS runs are 225 and 206, respectively. In other words, an average of 4.2 and 3.8 explosive cyclones per month appear in the OS and SS runs, respectively. The averaged maximum deepening rates are $1.77 \mathrm{hPa} \mathrm{hr}^{-1}$ and $1.79 \mathrm{hPa} \mathrm{hr}^{-1}$ for the OS and SS runs, respectively. Figures $2 \mathrm{a}, \mathrm{b}$ show the frequency distribution of explosive cyclone tracks during the 18 winters in the OS and SS runs, respectively. Explosive cyclone tracks tend to concentrate along the Kuroshio to the south of Japan in the OS run more than in the SS run. The cyclone track over the Japan Sea also concentrates in the OS run to some extent. The difference in the cyclone track frequency between the two SST runs (Fig. 2c) reveals that, over the surrounding oceans of Japan, the track frequency is higher in the OS run. Comparing these figures with Fig. 1 of Yoshiike and Kawamura (2009), the OS run performs better than the SS run.

The geographical concentration of cyclone occurrence in the vicinity of the East China Sea is considered as a major reason for the cyclone track along the Kuroshio, as inferred from Fig. 2. We next examine the cyclogenesis around that region and its relation to the baroclinicity in the lower troposphere with respect to each run. As a useful measure of the baroclinicity in the lower troposphere, the horizontal gradient of equivalent potential temperature $\theta_{e}\left(\sqrt{\left(\partial \theta_{e} / \partial x\right)^{2}}+\left(\partial \theta_{e} / \partial y\right)^{2}\right)$ is used in this study, as in Shiota et al. (a) OS run
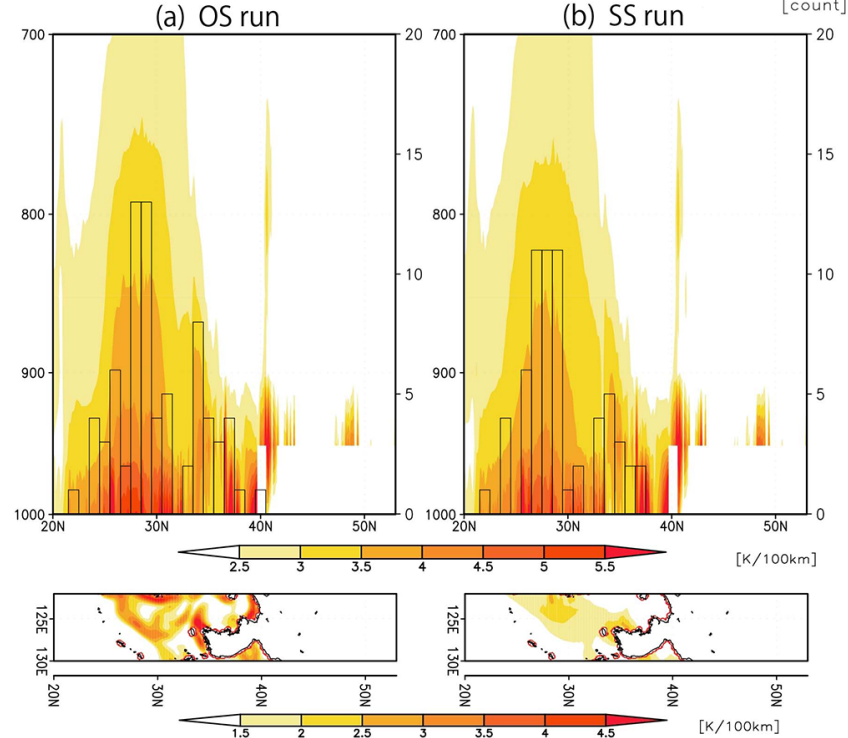

Fig. 3. (a) Latitude-height section of the horizontal $\theta_{e}$ gradient along the $122^{\circ} \mathrm{E}-130^{\circ} \mathrm{E}$ longitude zone across the Kuroshio for the OS run, based on the climatology of the 18 winters. Shading interval is $0.5 \mathrm{~K} / 100 \mathrm{~km}$. The latitudinal distribution of the total number of cyclone occurrences within the $122^{\circ} \mathrm{E}-130^{\circ} \mathrm{E}$ zone is shown by a bar graph. Exhibited, also, is the horizontal SST gradient in the East China Sea. The shading interval is $0.5 \mathrm{~K} / 100 \mathrm{~km}$. (b) As in Fig. 3a but for the SS run.

(2011). The upper panels of Fig. 3 reveal the latitude-height cross section of the wintertime horizontal $\theta_{e}$ gradient along the $122^{\circ} \mathrm{E}-$ $130^{\circ} \mathrm{E}$ longitude zone in the two runs, together with the latitudinal distribution of the total number of cyclone occurrences over the 18 winters within the corresponding zone. As for the cyclone occurrence, two dominant peaks can be clearly seen around $28^{\circ} \mathrm{N}-$ $29^{\circ} \mathrm{N}$ and $34^{\circ} \mathrm{N}$ in both the OS and SS runs. These peaks coincide well with the maximum areas of the horizontal $\theta_{e}$ gradient in the lower troposphere, particularly the lower levels near the ocean surface, suggesting that the lower tropospheric baroclinicity is indeed important for the wintertime cyclogenesis over the East China Sea. Another indication is that the two dominant peaks of cyclone occurrence are sharper in the OS run than in the SS run. The corresponding large $\theta_{e}$ gradient area also reaches higher altitudes in the OS run than in the SS run. In addition, the enhanced lower tropospheric baroclinicity is intimately associated with the horizontal SST gradient over the East China Sea. The lower panels of Fig. 3 show the horizontal SST gradient around the East China Sea in the two runs. The OS run has broad areas characterized by a large SST gradient. We stress that the steepness of the SST gradient in the OS run gives rise to the intensification of the lower tropospheric baroclinicity, eventually bringing about the geographical concentration of cyclone occurrence over the East China Sea. (a) OS run

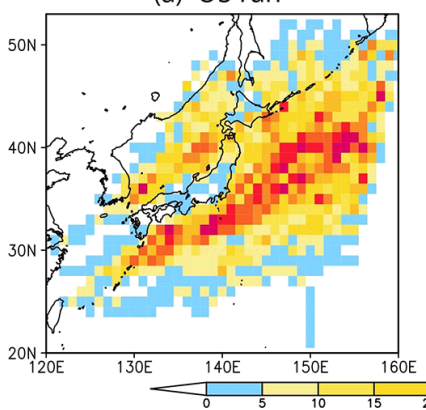

(b) SS run

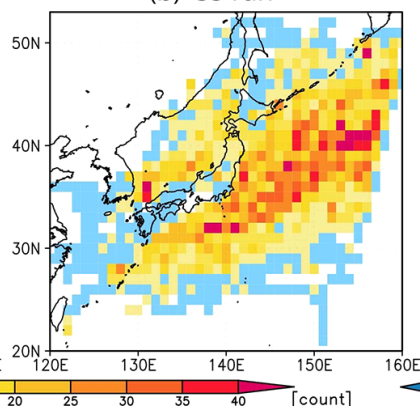

(c) Difference

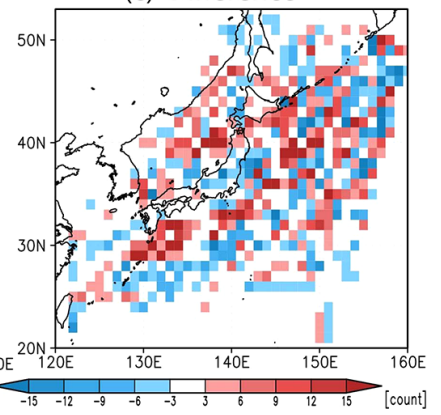

Fig. 2. (a) Frequency distribution of explosive cyclone tracks during the 18 winters for the OS run. It is noteworthy that the track is traced from the initial appearance through the disappearance of a cyclone that became an explosive cyclone. (b) As in Fig. 2a but for the SS run. (c) Difference in the cyclone track frequency between the OS and SS runs (former minus latter). 


\subsection{Explosive cyclone activity related to the winter monsoon intensity}

To determine how the East Asian winter monsoon variability regulates the explosive cyclone activity around Japan under two different SST conditions, we conducted composite analyses with respect to the strong and weak monsoon conditions. As an appropriate measure of the East Asian winter monsoon intensity, we used a simple index defined as the difference in SLP between Irkutsk in Russia and Nemuro in Japan (Irkutsk minus Nemuro) (Hanawa et al. 1989) on the basis of the JRA-25 and JCDAS data. After the monthly mean index series are standardized with regard to each winter month (December, January, and February), we defined a month for which the index is greater than +1.0 (less than -1.0 ) as a strong (weak) monsoon category. As a consequence, we extracted ten strong monsoon categories and nine weak monsoon categories, as indicated in Table 1 . Figure 4 shows the explosive cyclone tracks under strong and weak winter monsoon conditions for the OS run along with the locations of explosive cyclones when their rates of development reached the maximum. An immediate indication is the definitive difference in the explosive cyclone activity between the strong and weak monsoon conditions. When the monsoon is strong, the cyclogenesis tends to concentrate over the surrounding oceans of Japan. When the monsoon is weak, in contrast, individual explosive cyclone tracks spread out, and most of the cyclones reach the maximum deepening rates far away from Japan. These features are quite consistent with the observational results of Yoshiike and Kawamura (2009), hence confirming that the monsoon variability regulates the explosive cyclone activity around Japan to a large extent.

Composite maps of the maximum Eady growth rate under the strong and weak monsoon conditions for the OS run are also indicated in Fig. 4. It is noteworthy that the maximum Eady growth rate (Lindzen and Farrell 1980) is evaluated for the layer between the 850 - and $700-\mathrm{hPa}$ levels, which also represents the baroclinicity in the lower troposphere. Focusing on the areas exceeding $+1.0 \mathrm{~K} \mathrm{day}^{-1}$, under the strong monsoon conditions, those areas are located over the central Japan Sea and along the

Table 1. Strong and weak monsoon categories extracted on the basis of the standardized monthly mean monsoon intensity index.

\begin{tabular}{cl}
\hline Category & \multicolumn{1}{c}{ Month/Year } \\
\hline \multirow{2}{*}{ Strong monsoon } & $2 / 1994,1 / 1996,2 / 1996,12 / 2001,2 / 2005,12 / 2005$, \\
& $1 / 2008,1 / 2010,12 / 2010,1 / 2011$ \\
\multirow{2}{*}{ Weak monsoon } & $1 / 1994,12 / 1996,12 / 1997,2 / 1998,12 / 1998,1 / 2002$, \\
& $2 / 2003,12 / 2006,2 / 2007$ \\
\hline
\end{tabular}

(a) Strong monsoon

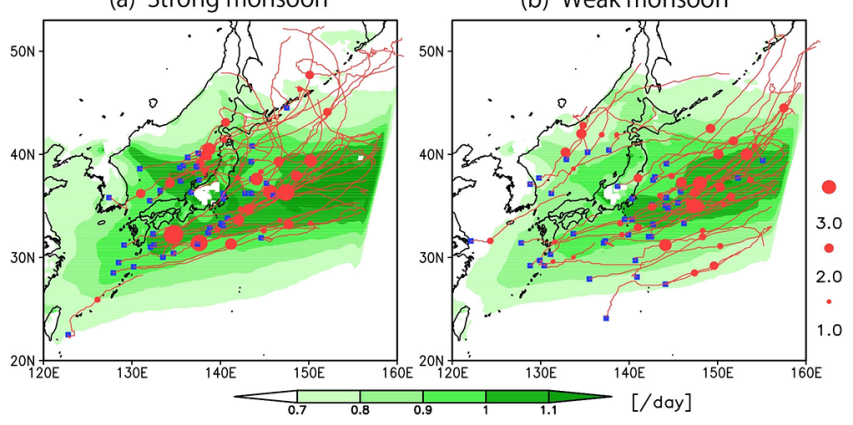

Fig. 4. (a) Tracks of explosive cyclones under the strong winter monsoon conditions for the OS run. Note that the track is traced from the initial appearance through the disappearance of a cyclone that became an explosive cyclone. The location of the initial appearance of a cyclone is denoted by blue rectangles. The locations of explosive cyclones when their rates of development reached the maximum are also shown by red circles. The size of the circles denotes the magnitude of the maximum deepening rate $\left(\mathrm{hPa} \mathrm{hr} \mathrm{h}^{-1}\right.$ ). A composite map of the maximum Eady growth rate is also shown. The shading interval is 0.1 day $^{-1}$. (b) As in Fig. 4a but for the weak monsoon conditions.
Kuroshio south of Japan. The zonally elongated baroclinic zone over the central Japan Sea corresponds to the so-called Japan-Sea polar-airmass convergence zone (JPCZ) (Asai 1988). The model is successful in resolving the JPCZ. The cyclogenesis concentrates near the JPCZ. Under the weak monsoon conditions, conversely, the growth rates become lower over the corresponding regions. It is noteworthy that the lower tropospheric baroclinicity change relevant to the monsoon intensity, which is represented by the maximum Eady growth rate, affects the geographical concentration and dispersion of the explosive cyclone activity in the vicinity of Japan. Similar features are also derived from the SS run (not shown). Thus, we confirm that the monsoon intensity is one of the major factors controlling the geography of the explosive cyclone activity.

Next, we compare the explosive cyclone activity under the strong monsoon conditions between the OS and SS runs, as indicated in Figs. 5a, b. We can find remarkable differences between the two runs regarding the strong monsoon conditions in terms of the cyclone track and the locations of cyclones when their rates of development reached the maximum. However, unfortunately, the maximum Eady growth rate cannot account for the significant differences in the cyclone activity under the strong monsoon conditions between the two runs because the growth rates are similar in each run (not shown). We thus consider an index, which is the horizontal $\theta_{e}$ gradient at the $900-\mathrm{hPa}$ level, as another measure of the lower tropospheric baroclinicity. For the OS run, the baroclinicity is enhanced along the Kuroshio and the Kuroshio Extension region with large horizontal $\theta_{e}$ gradients at the $900-\mathrm{hPa}$ level (Fig. 5a). Associated with this enhancement, the surface cyclogenesis in the OS run tends to concentrate in the vicinity of those areas (Fig. 5a). Focusing on the Japan Sea region, we can also see the intensified baroclinicity around the subpolar oceanic front at $40^{\circ} \mathrm{N}$ in the OS run. In contrast, the weakened baroclinicity and associated dispersion of the explosive cyclone activity characterize the SS run (Fig. 5b). It is apparent that the differences in the explosive cyclone activity under the strong monsoon conditions between the two runs are attributed to the change in the near-surface barocli- (a) OS run Strong monsoon

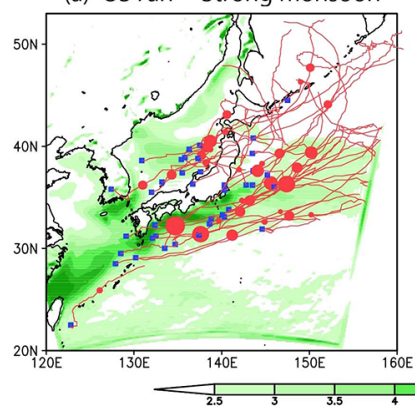

(c) Difference in $\Delta \theta_{\mathrm{e}} 900$

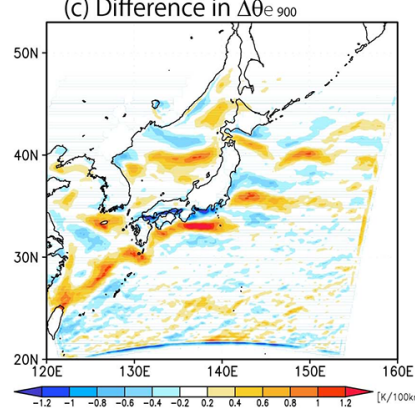

(b) SS run Strong monsoon

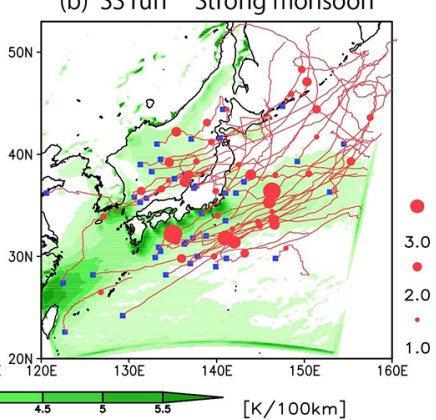

(d) Difference in SHF

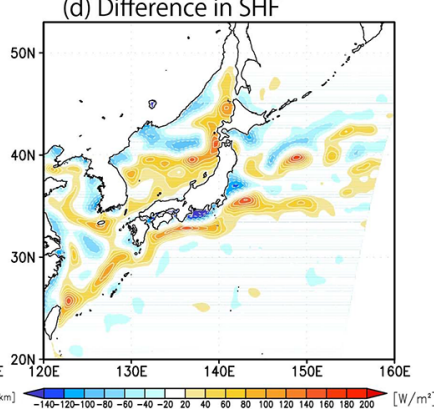

Fig. 5. (a) Composite map of the horizontal gradient of $900-\mathrm{hPa} \theta_{e}$ under the strong monsoon conditions for the OS run, along with the explosive cyclone tracks. The shading interval is $0.5 \mathrm{~K} / 100 \mathrm{~km}$. (b) As in Fig. 5a but for the SS run. (c) Composite difference in the horizontal gradient of 900$\mathrm{hPa} \theta_{e}$ under the strong monsoon conditions between the OS and SS runs (former minus latter). The shading interval is $0.2 \mathrm{~K} / 100 \mathrm{~km}$. (d) As in Fig. $5 \mathrm{c}$ but for the surface turbulent heat flux. The shading interval is $20 \mathrm{~W} \mathrm{~m}^{-2}$. 
nicity.

The composite difference in the surface turbulent heat flux between the OS and SS runs is shown in Fig. 5d. A notable feature is that increased surface heat (sensible and latent heat) flux areas in the OS run are located at the southern edge of the enhanced horizontal gradient of $900-\mathrm{hPa} \theta_{e}$ (Fig. 5c). This strongly suggests that the increased heat and moisture release from the ocean surface is responsible for the reinforcement of the horizontal $\theta_{e}$ gradient at the $900-\mathrm{hPa}$ level. Thus, we anticipate that the presence of the Kuroshio front, the Kuroshio Extension front, and the Japan Sea subpolar front, which is well defined by the OS run, leads to further concentration of the explosive cyclone activity along those fronts when the monsoon is strong.

It is interesting to note that there are no remarkable differences in the explosive cyclone activity under weak monsoon conditions between the two SST runs. The change in the SST gradient is not likely to have a significant impact on the cyclogenesis under the weak monsoon conditions. Furthermore, the differences in the horizontal $900-\mathrm{hPa} \theta_{e}$ gradient and the surface turbulent heat flux between the two runs tend to be small under the weak monsoon conditions (not shown). These results suggest that the possible effect of the SST fronts becomes more evident under the strong monsoon conditions through the increase in the heat and moisture fluxes from the ocean surface and associated enhanced near-surface baroclinicity.

Previous studies suggest that surface fluxes enhance the potential for rapid storm development in the precyclogenesis stage by increasing the available moisture, enhancing the low-level baroclinicity associated with strong SST gradients (e.g., Kuo et al. 1991). Thus, we may need to evaluate the robustness of the response by comparing the results using different PBL and surface parameterization schemes. This is because the choice of PBL and surface flux parameterizations can substantially affect temperature and moisture profiles in the lower atmosphere. In this study, we performed another long-term simulation over the same period, replacing the PBL scheme used in this study with the MellorYamada-Nakanishi-Niino scheme proposed by Nakanishi and Niino (2004). The simulated explosive cyclone activity was very similar to that shown in this study, which is quite consistent with the findings presented in this study.

\section{Summary}

Using a regional atmospheric model, we performed long-term simulations of wintertime explosive cyclone activity in the vicinity of Japan over 18 winters (DJF) from 1993/94 to 2010/2011 under two different boundary conditions of SST, i.e., the original SST (OS) run and the spatially smoothed SST (SS) run. By comparing the OS and SS runs, we find that the SST fronts play an influential role in the geographical concentration of the explosive cyclone activity in the vicinity around Japan. The geographical concentration (dispersion) of the explosive cyclone activity around Japan under the strong (weak) winter monsoon conditions is also simulated, and the simulation is quite consistent with the observed features (Yoshiike and Kawamura 2009). Under the strong monsoon conditions, the Kuroshio front, the Kuroshio Extension front, and the Japan Sea subpolar front give rise to enhanced near-surface baroclinicity through the increase in heat and moisture fluxes from the ocean surface and, as a consequence, lead to further concentration of the explosive cyclone activity along those fronts. It is also found that, under the weak monsoon conditions, in contrast, the influence of the SST fronts on the explosive cyclone activity is not evident.

We used two different indices, the maximum Eady growth rate and the horizontal $\theta_{e}$ gradient, as an appropriate measure of the baroclinicity in the lower troposphere, but there are some discrepancies between the two indices, especially with respect to the baroclinicity change between the OS and SS runs. As it is not easy to determine the most appropriate index of the baroclinicity, further clarification is required. This study emphasizes a passive role of the SST fronts in the explosive cyclone activity under the strong winter monsoon conditions. Iizuka (2010) demonstrated that the interannual SST variation over the Kuroshio-Oyashio Extension region can affect that of local precipitation. It is also possible that the variability of the SST fronts plays an active role in the surface cyclogenesis; studies in this regard are currently underway.

\section{Acknowledgments}

Comments by anonymous reviewers were extremely helpful. This research was supported by JSPS KAKENHI (22310111) and MEXT KAKENHI (22106005).

\section{References}

Asai, T., 1988: Meso-scale features of heavy snowfalls in Japan Sea coastal regions of Japan. Tenki, 35, 156-161. (in Japanese)

Chen, S.-J., Y.-H. Kuo, P.-Z. Zhang, and Q.-F. Bai, 1992: Climatology of explosive cyclones off the East Asian coast. Mon. Wea. Rev., 120, 3029-3035.

Chou, M.-D., and M. J. Suarez, 1994: An efficient thermal infrared radiation parameterization for use in general circulation models. NASA Tech. Memo., TM-104606, vol. 3, 84 pp.

Hanawa, K., Y. Yoshikawa, and T. Watanabe, 1989: Composite analyses of wintertime wind stress vector fields with respect to SST anomalies in the western North Pacific and the ENSO events. Part I: SST composite. J. Meteor. Soc. Japan, 67, 385-400.

Hong, S.-Y., Y. Noh, and J. Dudhia, 2006: A new vertical diffusion package with an explicit treatment of entrainment processes. Mon. Wea. Rev., 134, 2318-2341.

Iizuka, S., 2010: Simulations of wintertime precipitation in the vicinity of Japan: Sensitivity to fine-scale distributions of sea surface temperature. J. Geophys. Res., 115, D10107, doi:10.1029/2009JD012576.

Kain, J. S., and J. M. Fritsch, 1990: A one-dimensional entraining/detraining plume model and its application in convective parameterization. J. Atmos. Sci., 47, 2784-2802, doi:10.1175/1520-0469.

Kuo, Y. H., R. J. Reed, and S. Low-Nam, 1991: Effects of surface energy fluxes during early development and rapid intensification stages of seven explosive cyclones in the western Atlantic. Mon. Wea. Rev., 119, 457-476.

Lindzen, R. S., and B. Farrell, 1980: A simple approximate result for the maximum growth rate of baroclinic instabilities. J. Atmos. Sci., 37, $1648-1654$

Mlawer, E. J., S. J. Taubman, P. D. Brown, and M. J. Iacono, 1997: Radiative transfer for inhomogeneous atmospheres: RRTM, a validated correlated-k model for the longwave. J. Geophys. Res., 102, 16663-16682, doi:10.1029/97JD00237.

Morrison, H., J. A. Curry, and V. I. Khvorostyanov, 2005: A new double-moment microphysics parameterization for application in cloud and climate models: Part I. Description. J. Atmos. Sci., 62, 1665-1677, doi:10.1175/JAS3446.1.

Nakanishi, M., and H. Nino, 2004: An improved Mellor-Yamada level3 model with condensation physics: Its design and verification. Boundary-Layer Meteorology, 112, 1-31.

Onogi, K., et al., 2007: The JRA-25 reanalysis. J. Meteorol. Soc. Jpn., 85, 369-432.

Reynolds, R. W., T. M. Smith, C. Liu, D. B. Chelton, K. S. Casey, and M. G. Schlax, 2007: Daily high-resolution-blended analyses for sea surface temperature. J. Clim., 20, 5473-5496.

Shiota, M., R. Kawamura, H. Hatsushika, and S. Iizuka, 2011: Influence of the East Asian winter monsoon variability on the surface cyclogenesis over the East China Sea in late winter. SOLA, 7, 129-132.

Skamarock, W. C., J. B. Klemp, J. Dudhia, D. O. Gill, D. M. Barker, M. Duda, X.-Y. Huang, W. Wang, and J. G. Powers, 2008: A description of the advanced research WRF version 3. NCAR Technical Note.

Xie, S.-P., J. Hafner, Y. Tanimoto, W. T. Liu, H. Tokinaga, and H. Xu, 2002: Bathymetric effect on the winter sea surface temperature and climate of the Yellow and East China Seas. Geophys. Res. Lett., 29, 2228, doi:10.1029/2002GL015884.

Yoshida, A., and Y. Asuma, 2004: Structures and environment of explosively developing extratropical cyclones in the northwestern Pacific region. Mon. Wea. Rev., 132, 1121-1142.

Yoshiike, S., and R. Kawamura, 2009: Influence of wintertime large-scale circulation on the explosively developing cyclones over the western North Pacific and their downstream effects. J. Geophys. Res., 114, D13110, doi:10.1029/2009JD011820.

Manuscript received 27 August 2012, accepted 5 December 2012

SOLA: http://www.jstage.jst.go.jp/browse/sola 